\title{
MYOCARDIAL SUBSTRATE UPTAKE AND OXIDATION DURING AND AFTER ROUTINE CARDIAC SURGERY
}

H. G. Pietersen, MD

C. J. M. Langenberg, MD ${ }^{\mathrm{b}}$

G. Geskes, $\mathrm{MD}^{\mathrm{c}}$

A. Kester, $\mathrm{pHD}^{\mathrm{d}}$

S. de Lange, Professor ${ }^{b}$

G. J. Van der Vusse, Professor ${ }^{\mathrm{e}}$

A. J. M. Wagenmakers, pHD $^{\mathrm{f}}$

P. B. Soeters, Professor ${ }^{\mathrm{a}}$
Objective: This study was designed to clarify whether myocardial substrate uptake and oxidation change after a period of hypothermic cardioplegic arrest during coronary artery bypass grafting procedures. Methods: In 30 patients arterial and coronary sinus blood was sampled and coronary sinus flow measurements were performed before and after sternotomy and 10 minutes, 20 minutes, 50 minutes, and 6 hours after release of the aortic crossclamp. Measurement of free fatty acids, lactate, glucose, oxygen content, and carbon dioxide content in arterial and coronary sinus blood allowed calculations of myocardial substrate use, respiratory quotients, and myocardial oxidation rates of carbohydrates and fat. Results: Uptake of free fatty acids and lactate was significant throughout the study and did not change in association with release of the crossclamp. Free fatty acid and lactate uptake measured $6 \pm 4$ $\mu \mathrm{mol} / \mathrm{min}$ and $23 \pm 26 \mu \mathrm{mol} / \mathrm{min}$, respectively, before crossclamping compared with $8 \pm 7 \mu \mathrm{mol} / \mathrm{min}$ and $19 \pm 21 \mu \mathrm{mol} / \mathrm{min}$, respectively, after release of the clamp. Glucose uptake was significant only during the first hour after crossclamp release and increased from $7 \pm 50$ to $28 \pm 34$ $\mu \mathrm{mol} / \mathrm{L}$ after crossclamp release. Myocardial oxygen consumption did not change significantly $(0.5 \pm 0.2 \mathrm{mmol} / \mathrm{L}$ compared with $0.35 \pm 0.2$ $\mathrm{mmol} / \mathrm{L}$ ) after release of the crossclamp. Myocardial oxygen extraction ratio decreased from $58 \% \pm 8 \%$ to $41 \% \pm 13 \%$ after crossclamp release. Respiratory quotient increased after crossclamp release $(0.85 \pm 0.2 \mathrm{com}$ pared with $1.00 \pm 0.2$ ), which implies that carbohydrate oxidation increased at the expense of free fatty acid oxidation. Conclusion: We conclude that hypothermic cardioplegic arrest during coronary artery bypass graft operations is associated with a transiently increased uptake and oxidation of carbohydrates during the immediate reperfusion phase. (J Thorac Cardiovasc Surg 1999;118:71-80)
U

nder normal physiologic circumstances, cardiac muscle uses fatty acids, lactate, and glucose as main substrates to fulfill its energy requirements. ${ }^{1-3}$ During restriction of coronary flow (ischemia) that leads to

From the Departments of Surgery, ${ }^{\mathrm{a}}$ Anesthesiology, ${ }^{\mathrm{b}}$ and CardioThoracic Surgery, ${ }^{\mathrm{c}}$ University Hospital Maastricht, and the Departments of Statistics and Informatics, ${ }^{\mathrm{d}}$ Human Biology, ${ }^{\mathrm{f}}$ and Physiologye of the Cardiovascular Research Institute, University of Maastricht, Maastricht, The Netherlands.

Received for publication Sept 1, 1998; revisions requested Nov 6, 1998; revisions received March 17, 1999; accepted for publication March 17, 1999.

Address for reprints: H. G. Pietersen, Department of Surgery, University Hospital Maastricht, PO Box 5800 AZ, Maastricht, The Netherlands.

Copyright $(1) 1999$ by Mosby, Inc.

$0022-5223 / 99 \$ 8.00+0 \quad \mathbf{1 2 / 1 / 9 8 5 8 7}$ shortage of oxygen for the cardiac myocytes, fatty acid metabolism is severely impaired. ${ }^{4}$ Oxygen deprivation leads to a diminished $\beta$-oxidation of fatty acids, whereas glucose competes favorably with fatty acids for the residual oxygen, which is supplied to the heart in greatly reduced amounts. ${ }^{5}$ In addition, glycolytic activity is enhanced, leading to the accumulation of lactate in flow-deprived tissues.

In animal studies, reperfusion of cardiac tissue after a relatively short period of ischemia resulted in rapid restoration of the capacity to oxidize fatty acids. ${ }^{6-8}$ Restoration of flow after an ischemic interval longer than 60 minutes was found to be associated with depressed fatty acid oxidation and enhanced use of carbohydrates in the previously ischemic area. ${ }^{9}$ These findings strongly suggest that the postischemic ability to restore the ability of the cardiac muscle to handle fatty 
acids depends on the severity of the preceding ischemic episode. ${ }^{1}$

During cardiac surgery, aortic crossclamping results in an almost complete cessation of blood flow through the coronary arteries. Although measures are taken to protect the myocardium by hypothermia and electromechanical arrest, myocardial ischemia will occur. Removal of the aortic crossclamp restores blood supply to the heart and, hence, the delivery of molecular oxygen and oxidizable substrates to the cardiac muscle cells. At present, it is not clear whether the use of fatty acids and glucose is immediately restored to preoperative levels in the human heart after cardiac surgery. Some studies indicated a normalization of fatty acid uptake $^{10}$ but a decline in oxidation in the first hours after restoration of myocardial perfusion. Others, however, did not find a significant use of fatty acids and carbohydrates after release of the aortic crossclamp. ${ }^{11,12}$

More knowledge of metabolic changes after myocardial ischemia is necessary to optimize the treatment of patients undergoing cardiac surgery. The aim of this study is therefore to investigate whether substrate uptake and oxidation of the heart changes after a period of hypothermic global ischemia during routine cardiac surgery. For this purpose, metabolite, oxygen, and carbon dioxide exchange across the heart was measured to investigate the exchange of fuels and to calculate carbohydrate and fat oxidation from the respiratory quotients.

\section{Methods}

Patient population and selection. The patients in this study had proved symptomatic coronary artery disease (New York Heart Association classes III and IV) and had been referred to a university hospital for operative revascularization. Before the operation all patients were treated with $\beta_{1}$ blocking agents and $\mathrm{Ca}^{++}$-reentry blockers. All other oral medication was discontinued the evening before the operation. Only patients with preserved left ventricular function (ejection fraction $>50 \%$ ) were included in this study. Patients with diabetes mellitus, thyroid diseases, hepatic insufficiency, renal insufficiency, and therapy-resistant hypertension were excluded from the study. Patients with heart failure and significant cardiac valvular disorders and patients using systemic corticosteroids were also excluded. The local ethical review board approved the study. Written informed consent was obtained from all patients.

\section{Clinical management}

Anesthesia. After overnight fasting, the patients were premedicated with lorazepam $(0.03-0.06 \mathrm{mg} / \mathrm{kg})$. Anesthesia was induced with midazolam $(0.06-0.08 \mathrm{mg} / \mathrm{kg})$, sufentanil $(1-1.5 \mu \mathrm{g} / \mathrm{kg})$, and etomidate $(0.2-0.3 \mathrm{mg} / \mathrm{kg})$. Pancuronium bromide (Pavulon, $0.1 \mathrm{mg} / \mathrm{kg}$ ) was infused to induce muscle relaxation. Anesthesia was maintained with sufentanil, 0.5 $\mu \mathrm{g} / \mathrm{kg}$ per hour, before extracorporeal circulation (ECC), 2.5 $\mu \mathrm{g} / \mathrm{kg}$ per hour during ECC, and $1.25 \mu \mathrm{g} / \mathrm{kg}$ per hour after ECC. Nitroglycerin $(0.5 \mu \mathrm{g} / \mathrm{kg}$ per minute) was started after induction of anesthesia and was continued throughout the operation. Postoperatively, patients were kept sedated with midazolam. For postoperative analgesia, alfentanil (Rapifen, 2-3 $\mathrm{mL} / \mathrm{h}$ ) was given when necessary.

$E C C$. After sternotomy, heparin was given in a dose of 3 $\mathrm{mg} / \mathrm{kg}$. The ECC was performed with a roller pump (Stöckert Shiley, Munich, Germany) giving a pulsatile flow and a hollow-fiber oxygenator (Capiox SX, Terumo Corp, Tokyo, Japan). Moderate hypothermia $\left(28^{\circ} \mathrm{C}-32^{\circ} \mathrm{C}\right)$ was routinely applied during aortic crossclamping.

Cold crystalloid cardioplegic solution according to the St Thomas' Hospital method was used to arrest the heart ${ }^{13}$ via the aortic root. Electrical silence of the heart was maintained throughout the period of crossclamping. When the aortic crossclamp time exceeded 60 minutes or electrical activity occurred, extra cardioplegic solution $(5-8 \mathrm{~mL} / \mathrm{kg})$ was given. The solution contained (in millimoles per liter) sodium chloride (101.2), potassium chloride (16.2), magnesium sulphate (1.3), magnesium chloride-6-hydrate (15.9), potassium hydrogen phosphate (1.3), calcium chloride-2-hydrate (1.3), procaine hydrochoride (1.1), and potassium bicarbonate (25). ECC was terminated after rewarming to a rectal temperature of $35^{\circ} \mathrm{C}$. No inotropic drugs were used during weaning from bypass. Protamine sulphate $(3 \mathrm{mg} / \mathrm{kg})$ was continuously infused over 15 minutes immediately after weaning from bypass to counteract the effect of heparin.

Study protocol. An arterial line was inserted in the left radial artery. After induction of anesthesia, a pulmonary artery catheter and a Baim coronary sinus thermodilution catheter $^{14}(7 \mathrm{~F})$ were inserted via the right internal jugular vein. Under fluoroscopic control and continuous monitoring of distal tip pressures, the coronary sinus catheter tip was placed approximately 4 to $6 \mathrm{~cm}$ into the coronary sinus. Correct positioning of the tip of the coronary sinus catheter was verified by comparison of coronary sinus and mixed venous blood oxygen saturation. This setting enabled us to measure myocardial arteriovenous concentration differences across the heart.

Hemodynamic measurements, coronary sinus blood flow, and arterial and coronary sinus blood samples were taken before (T1) and after (T2) incision and at the following times after removal of the crossclamp: 10 minutes (T3), 20 minutes (T4), 50 minutes (T5), and 6 hours (T6).

No cardiac output measurements were performed 10 minutes after removal of the crossclamp (T3) while patients were being weaned from bypass. Measurements of gaseous exchange were performed in a subgroup of 18 patients. Because no differences were found between $\mathrm{T} 1$ and $\mathrm{T} 2$, the data at these two times were pooled and compared with the pooled data of $\mathrm{T} 4$ and $\mathrm{T} 5$. The data obtained 10 minutes after removal of the crossclamp (T3) were omitted from the analysis because during this measurement the hearts were being weaned from ECC. The measured variance at this point was 
extremely high, making it likely that there was no intracellular steady state of substrates, which is a prerequisite to arrive at reliable calculations and to acquire meaningful answers. After transfer of the patients to the intensive care unit, the position of the catheter in the coronary sinus was checked again as described earlier.

Sample handling. Blood samples for biochemical analysis were taken simultaneously from the radial artery and coronary sinus. Samples for free fatty acids (FFAs) and glycerol analysis were collected in ethylenediaminetetraacetic acid tubes. Other samples were collected in sodium heparin tubes. The samples were immediately centrifuged at $4^{\circ} \mathrm{C}$, and the plasma was frozen in liquid nitrogen and then stored at $-80^{\circ} \mathrm{C}$ until analysis. Before the lactate and glucose samples were frozen, the protein was extracted from them by addition of 25 $\mu \mathrm{L}$ of a solution of trichloroacetic acid $(5 \mathrm{~g} / 10 \mathrm{~mL})$ to $250 \mu \mathrm{L}$ of plasma.

Biochemical analysis. Total plasma FFA concentration was determined with a Wako NEFA-C test kit (Wako Chemicals, Neuss, Germany) on a COBAS BIO centrifugal analyzer (Roche Diagnostics, Division of Hoffmann LaRoche Ltd, Basel, Switzerland). Glucose was enzymatically determined on a COBAS MIRA with a test kit (Roche, The Netherlands). ${ }^{15}$ Lactate was enzymatically determined on a COBAS-MIRA with the use of lactate dehydrogenase (Boehringer article number 127876). ${ }^{16}$ Blood oxygen saturation was directly measured with an OSM3 Hemoximeter (Radiometer A/S, Copenhagen, Denmark). Blood pH, carbon dioxide tension $\left(\mathrm{PCO}_{2}\right)$, and oxygen tension $\left(\mathrm{PO}_{2}\right)$ were measured with an ABL-505 device (Radiometer). Arterial and coronary sinus blood oxygen content was calculated from these variables by means of the following formula: $\mathrm{O}_{2}$ content $(\mathrm{mmol} / \mathrm{L})=$ hemoglobin $(\mathrm{Hgb})$ concentration $(\mathrm{mmol} / \mathrm{L})$ $\times\left(\mathrm{Ho}_{2} / \mathrm{Hgb}\right)+0.0105 \times \mathrm{Po}_{2}(\mathrm{kPa})$.

Total blood carbon dioxide content was directly measured with a Finnigan MAT 252 GCC/IRMS mass spectrometer (Finnigan Corporation, Division of ThermoQuest, San Jose, Calif). Approximately $500 \mathrm{mg}$ of blood was accurately weighed into a 15-mL Vacutainer tube (Becton, Dickinson \& Company, East Rutherford, NJ). Carbon dioxide was liberated by addition of $0.5 \mathrm{~mL}$ sulphuric acid ( $1 \mathrm{~mol} / \mathrm{L})$ to the blood sample, the head space gas mixture in the Vacutainer tube was brought to atmospheric pressure by addition of helium, and then $50 \mu \mathrm{L}$ of the gas mixture was injected into a Poroplot GC column (Chromopack International, Bergen op Zoom, The Netherlands) connected on line to the IRMS mass spectrometer. The carbon dioxide concentration was determined by simultaneous analyses of $\mathrm{NaHCO}_{3}$ standards of known concentration. Hemoglobin and hematocrit values were determined with a Coulter MAXM-AL (Coulter Corporation, Mijdrecht, The Netherlands).

Flow measurements. Coronary sinus blood flow was measured by means of a retrograde continuous thermodilution technique. ${ }^{14}$ Saline solution $(0.9 \%)$ at room temperature was infused with a Medrad Mark V infusion pump (Medrad, Inc, Pittsburgh, Pa) at a rate of $50 \mathrm{~mL} / \mathrm{min}$ for 30 seconds. Flow measurements were performed before and after blood sam-
Table I. Characteristics of patients ( $n=30 ; 25$ male, 5 female) and operation conditions

\begin{tabular}{lc}
\hline & Mean $\pm S D$ \\
\hline Age (y) & $61.7 \pm 10.2$ \\
NYHA classification & $3.0 \pm 0.5$ \\
Number of grafts & $3.7 \pm 1.5$ \\
Crossclamp time (min) & $40.0 \pm 17.0$ \\
Volume of cardioplegic solution $(\mathrm{mL})$ & $695 \pm 250$ \\
ECC time (min) & $62 \pm 20$ \\
ECC flow (L/min) & $4.4 \pm 0.4$ \\
Lowest blood temperature during ECC $\left({ }^{\circ} \mathrm{C}\right)$ & $27.7 \pm 4$ \\
Lowest rectal temperature during ECC $\left({ }^{\circ} \mathrm{C}\right)$ & $32.6 \pm 2$ \\
\hline
\end{tabular}

$S D$, Standard deviation; NYHA, New York Heart Association; ECC, extracorporeal circulation.

pling. The average of two measurements was taken to be representative for the coronary sinus blood flow during the sampling period.

Calculations. Net uptake and release of substrates, oxygen, and carbon dioxide are calculated with the following formula:

(Arterial concentration - Coronary sinus concentration) $\times$ Coronary sinus flow

Coronary sinus blood flow was used for variables determined in whole blood, whereas plasma flow was used for calculation of fluxes of metabolites determined in plasma:

Plasma flow $=(1-$ Hematocrit $) \times$ Coronary sinus flow

A positive number means uptake of substrate, and a negative number means release of substrate by the heart.

\section{Extraction ratio.}

$$
\frac{[\mathrm{a}]-[\mathrm{cs}]}{[\mathrm{a}]} \times 100 \%=\frac{\Delta[\mathrm{a}-\mathrm{cs}]}{[\mathrm{a}]} \times 100 \%
$$

where $a=$ arterial concentration and $c s=$ coronary sinus concentration.

\section{Respiratory quotient.}

$$
\frac{\Delta[\mathrm{a}-\mathrm{cs}]\left(\mathrm{CO}_{2}\right) \times-1}{\Delta[\mathrm{a}-\mathrm{cs}]\left(\mathrm{O}_{2}\right)}
$$

Formulas used to calculate oxidation rates from myocardial gaseous exchange and formulas used to calculate substrate oxygen equivalents from myocardial substrate uptake are given in the appendix.

Statistics. Data in tables and figures are given as mean \pm standard deviation of the mean. Wilcoxon matched-pairs signed-ranks tests were used to test whether arterial-coronary sinus substrate differences were significant. Analysis of variance was used to determine whether variables showed significant changes during the study period. Wilcoxon matchedpairs signed-ranks tests were used as post hoc tests to determine whether events showed significant changes. To exclude that measured changes were due to surgical stress and not to cold cardioplegic arrest, we made a comparison 
Table II. Hemodynamic conditions ( $n=30$ patients) before, during, and up to 6 hours after $C A B G$

\begin{tabular}{|c|c|c|c|c|c|c|c|}
\hline & $\begin{array}{c}\text { Before incision } \\
\text { (T1) }\end{array}$ & & $\begin{array}{c}\text { After incision } \\
\text { (T2) }\end{array}$ & & $\begin{array}{c}15-20+X-O F F \\
\text { (T4) }\end{array}$ & $\begin{array}{c}50 \min +X-O F F \\
\text { (T5) }\end{array}$ & $\begin{array}{c}6 h+X-O F F \\
\text { (T6) }\end{array}$ \\
\hline MAP (mm Hg) & $77 \pm 12$ & & $77 \pm 14$ & & $69 \pm 10$ & $73 \pm 10$ & $75 \pm 11$ \\
\hline Wedge pressure $(\mathrm{mm} \mathrm{Hg})$ & $12 \pm 3.5$ & $*$ & $12 \pm 3.6$ & & $13 \pm 3.0$ & $13 \pm 3$ & $9 \pm 3$ \\
\hline Cardiac index $\left(\mathrm{L} / \mathrm{min} \cdot \mathrm{m}^{2}\right)$ & $2.3 \pm 0.6$ & $\dagger$ & $2.3 \pm 0.6$ & $\dagger$ & $3.2 \pm 0.7$ & $3.2 \pm 0.9$ & $3.1 \pm 0.7$ \\
\hline SVR $\left(\right.$ dyne $\left.\cdot \mathrm{s} \cdot \mathrm{m}^{2} / \mathrm{cm}^{5}\right)$ & $2496 \pm 755$ & $\dagger$ & $2471 \pm 714$ & $\ddagger$ & $1541 \pm 400$ & $1701 \pm 525$ & $1839 \pm 456$ \\
\hline Rate pressure product (mm Hg/min) & $4609 \pm 1284$ & $\dagger$ & $5344 \pm 1745$ & & $5460 \pm 938$ & $5963 \pm 1266$ & $7075 \pm 1815$ \\
\hline
\end{tabular}

$C A B G$, Coronary artery bypass grafting; $X-O F F$, crossclamp off; $M A P$, mean arterial blood pressure; $S V R$, systemic vascular resistance.

$* P=.03 \mathrm{~T} 1$ versus $\mathrm{T} 6$.

$\dagger P<.001 \mathrm{~T} 1$ versus $\mathrm{T} 6$.

$\ddagger P<.001 \mathrm{~T} 2$ versus $\mathrm{T} 4$.

Table III. Arterial concentrations, extractions ratios, and net uptake of FFA, lactate, and glucose ( $n=30$ patients)

\begin{tabular}{|c|c|c|c|c|c|c|c|c|c|c|c|}
\hline & $\begin{array}{l}\text { Before } \\
\text { incision } \\
(T 1)\end{array}$ & & $\begin{array}{l}\text { After } \\
\text { incision } \\
(T 2)\end{array}$ & & $\begin{array}{c}X-O F F+ \\
10 \mathrm{~min} \\
(\mathrm{T3})\end{array}$ & & $\begin{array}{c}X-O F F+ \\
20 \mathrm{~min} \\
(T 4)\end{array}$ & & $\begin{array}{c}X-O F F+ \\
50 \mathrm{~min} \\
(T 5)\end{array}$ & & $\begin{array}{c}X-O F F+ \\
6 h \\
(T 6)\end{array}$ \\
\hline FFA arterial concentration $(\mu \mathrm{mol} / \mathrm{L})$ & $384 \pm 243$ & & $418 \pm 243$ & $\S$ & $422 \pm 192$ & $\|$ & $274 \pm 189$ & & $200 \pm 178$ & & $380 \pm 157$ \\
\hline FFA extraction ratio (\%) & $28 \pm 9$ & & $23 \pm 12$ & & $16 \pm 12$ & & $16 \pm 15$ & & $14 \pm 13$ & & $28 \pm 11$ \\
\hline FFA uptake ( $\mu \mathrm{mol} / \mathrm{min})$ & $8 \pm 6$ & & $6 \pm 4$ & & $8 \pm 7$ & & $6 \pm 7$ & & $4 \pm 5$ & & $12 \pm 8$ \\
\hline Lactate arterial concentration $(\mathrm{mmol} / \mathrm{L})$ & $1.4 \pm 0.5$ & II & $1.3 \pm 0.5$ & & $1.4 \pm 0.4$ & & $1.4 \pm 0.4$ & & $1.3 \pm 0.3$ & & $1.0 \pm 0.3$ \\
\hline Lactate extraction ratio (\%) & $31 \pm 18$ & & $23 \pm 30$ & & $14 \pm 11$ & $\|$ & $14 \pm 13$ & & $21 \pm 14$ & & $24 \pm 13$ \\
\hline Lactate uptake $(\mu \mathrm{mol} / \mathrm{min})$ & $32 \pm 22$ & & $23 \pm 26$ & & $19 \pm 21$ & $\|$ & $24 \pm 23.1$ & & $39 \pm 27$ & & $26 \pm 20$ \\
\hline tration $(\mathrm{mmol} / \mathrm{L})$ & $9.64 \pm 2.4$ & \# & $10.14 \pm 3.2$ & $*+$ & $8.14 \pm 2.0$ & $\|$ & $8.49 \pm$ & & $8.37=$ & & $5.88 \pm 1.0$ \\
\hline Glucose extraction ratio (\%) & $0.5 \pm 3.6$ & & $0.7 \pm 4.4$ & & $3.3 \pm 3.6$ & & $2.2 \pm 3.8$ & & $0.9 \pm 2.2$ & & $0.9 \pm 3.3$ \\
\hline Glucose uptake $(\mu \mathrm{mol} / \mathrm{min})$ & $4 \pm 24$ & & $7 \pm 50$ & $\dagger$ & $28 \pm 34$ & $*$ & $23 \pm 38$ & $* *$ & $10 \pm 25$ & & $5 \pm 16$ \\
\hline
\end{tabular}

$X$-OFF, Crossclamp off; $F F A$, free fatty acids.

$* P<.001 \mathrm{~T} 2$ versus $\mathrm{T} 3$.

$\dagger P=.025 \mathrm{~T} 2$ versus $\mathrm{T} 3$.

$¥ P=.005 \mathrm{~T} 2$ versus $\mathrm{T} 4$.

$\S P=.015 \mathrm{~T} 2$ versus $\mathrm{T} 4$.

$\| P<.001 \mathrm{~T} 3$ versus T5.

IIP $=.01 \mathrm{~T} 1$ versus $\mathrm{T} 6$.

$\# P<.001 \mathrm{~T} 1$ versus $\mathrm{T} 6$.

**Significant glucose uptake

between T1 and T2. T2 was compared with T3 to evaluate changes after a period of cold cardioplegic arrest. Because at T3 the hearts were being weaned from ECC, a comparison was made between $\mathrm{T} 2$ and the first measurement after cardioplegic arrest without support of ECC (T4). The changes in the first hour after release of the crossclamp were studied by comparing T3 versus T5. Finally, T1 was compared with T6 to investigate whether metabolism was normalized 6 hours after release of the clamp. A Bonferroni correction for multiple comparisons was performed to limit the possibility of false positive significant changes (type I error) to 0.05 per variable studied. The data calculated from gaseous exchange were analyzed in a similar way. Because these data were pooled, only three periods were compared: before bypass, after bypass, and 6 hours after bypass. Bonferroni corrections were also made.

\section{Results}

Patient data (Table I). Patients were weaned from ECC without serious complications. In two patients defibrillation of the heart was necessary. No blood samples were taken during periods of fibrillation. Thirteen patients required temporary pacing with an external pacemaker because of low heart rates after weaning from ECC. Low peripheral resistance after release of the crossclamp resulting in low mean arterial blood pressures (mean arterial pressure $<60 \mathrm{~mm} \mathrm{Hg}$ ) prompted the use of phenylephrine in seven patients. In one of these patients, norepinephrine $(5 \mu \mathrm{g} / \mathrm{kg}$ per minute) was also given. The mean hematocrit value was $0.35 \pm 0.04$ before bypass ( $\mathrm{T} 1$ and $\mathrm{T} 2$ ) and decreased to $0.24 \pm 0.03$ after bypass (T3). At the end of the study period (T6), the hematocrit value was 0.28 \pm 0.05 , which was lower than preoperative values.

Hemodynamic data (Table II). Pulmonary capillary wedge pressures were at preoperative levels until arrival in the postoperative intensive care unit. Thereafter, pulmonary wedge pressure decreased. The 


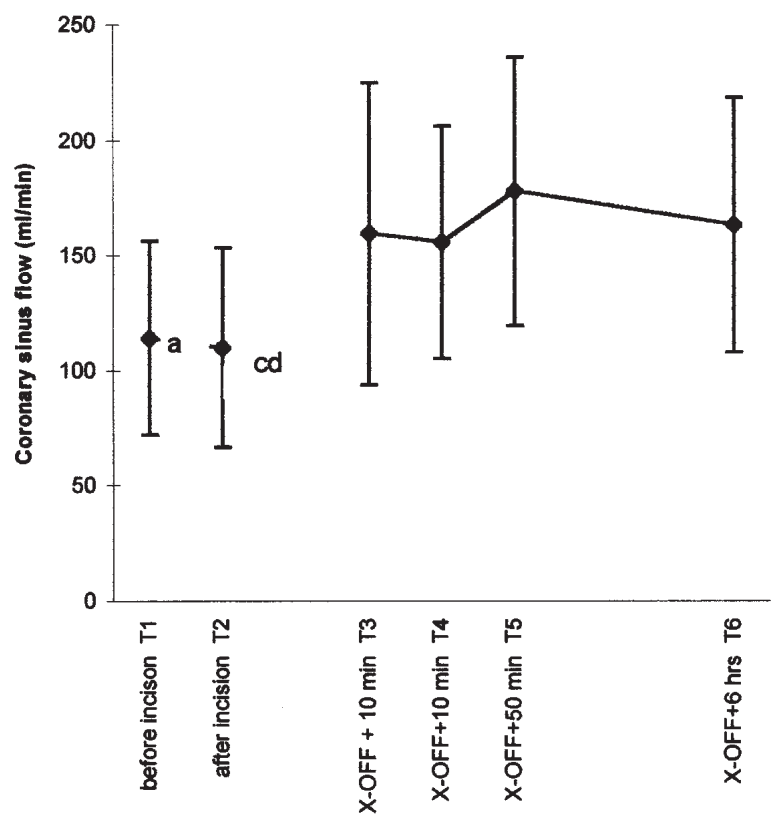

Fig 1. Coronary sinus flow in 30 patients. $P<.001: a$, T1 versus T6; $c$, T2 versus $\mathrm{T} 3 ; d$, T2 versus T4.

rate pressure product (mean arterial blood pressure $\times$ heart rate) did not significantly change after release of the crossclamp. Cardiac index increased after the clamp was removed and was higher at the end of the study period than before the operation.

Coronary sinus flow (Fig 1). Coronary sinus flow increased after removal of the crossclamp and remained elevated during the study period.

Substrate uptake and extraction by the heart (Table III)

FFA. The largest change in FFA arterial concentration occurred in the first hour after release of the aortic crossclamp when protamine was given to counteract the effects of heparinization (T3 vs T5). This resulted in a decline of the arterial FFA concentration with about 50\%. FFA uptake by the heart was significant throughout the study period. Incision and aortic crossclamping were not associated with significant changes in FFA uptake. The mean FFA extraction ranged from $28 \%$ (T1) to $14 \%$ (T5).

Lactate. At the end of the study period the arterial lactate concentration was lower than before the operation. Lactate uptake was significant throughout the study period. Incision and aortic crossclamping did not cause significant changes in lactate uptake. Lactate uptake increased in the hour after release of the aortic crossclamp (T3-T5). Mean lactate extraction ratio ranged from $31 \%$ (T1) to $14 \%$ (T3). After
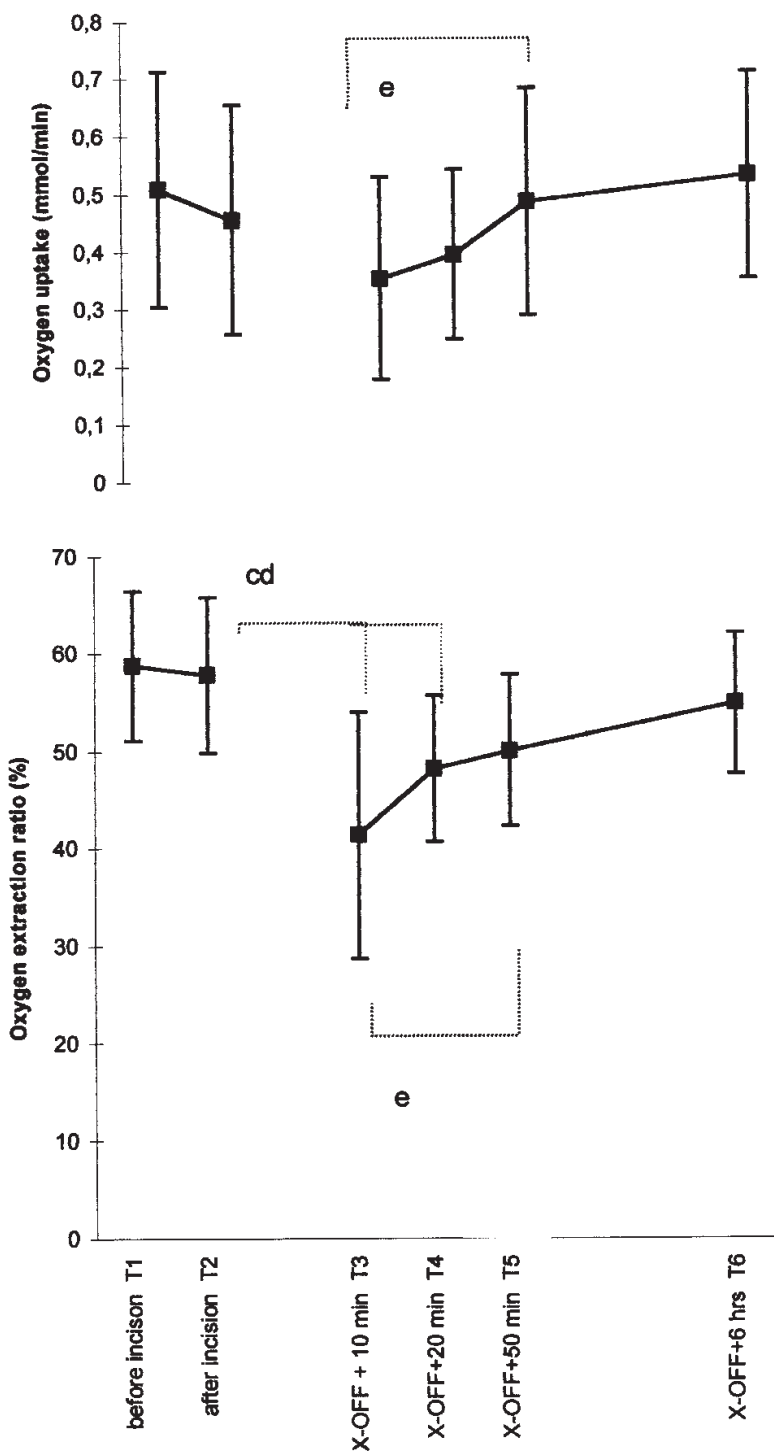

Fig 2. Oxygen uptake and oxygen extraction ratio in 30 patients. c $P<.001=\mathrm{T} 2$ versus T3; $\mathrm{d} P<.001 \mathrm{~T} 2$ versus T4; e $P=.01 \mathrm{~T} 3$ versus T5.

crossclamp release, lactate extraction ratio increased (T3-T5).

Glucose. After crossclamp release, the arterial glucose concentration was lower than before crossclamping. At the end of the study period, arterial glucose concentration dropped below preoperative levels. The mean glucose extraction ratio was low and ranged from $3 \%$ (T3) to 1\% (T1). Glucose uptake was significantly different from zero only during the first hour after removal of the crossclamp. A significant increase in glucose uptake was observed immediately after the crossclamp was removed (T2 vs T3). 




Fig 3. Substrate oxygen equivalents $\left(\mathrm{VO}_{2}\right.$ equivalents) in 30 patients as a percentage of the measured $\mathrm{VO}_{2} \mathrm{a}-\mathrm{cs}$. The calculations are made under the assumption that all substrates taken up by the heart are fully oxidized. a $P<.001$, glucose T2 versus T3; b $P=.02$, FFA T3 versus T5; c $P<.001$, total $\mathrm{Vo}_{2}$ equivalents $/ \mathrm{Vo}_{2} \mathrm{a}-\mathrm{cs}$, T2 versus T3; $P$ $<.001$, total $\mathrm{VO}_{2}$ equivalents $/ \mathrm{VO}_{2} \mathrm{a}-\mathrm{cs}$, $\mathrm{T} 3$ versus $\mathrm{T} 5$; $\# P<.05$, total $\mathrm{VO}_{2}$ equivalents $/ \mathrm{VO}_{2} \mathrm{a}-\mathrm{cs}$ significantly different from $100 \%$.

Oxygen uptake and extraction ratio by the heart (Fig 2). Oxygen uptake did not significantly change immediately after crossclamp removal (T3 and T4) compared with values before crossclamping. In the first hour after crossclamp release, oxygen uptake increased (T3-T5). Oxygen uptake was not significantly different from preoperative values at the end of the study period. Mean oxygen extraction ratio was $58 \%$ to $60 \%$ before and after incision. After crossclamp release, a decrease was observed in oxygen extraction ratio compared with values before aortic crossclamping. Oxygen extraction ratio was not significantly different from preoperative levels at the end of the study period.

Substrate oxygen equivalents (Fig 3). Fig 3 shows the potential contribution of glucose, lactate, and FFA taken up by the heart to myocardial oxygen consumption, assuming that the substrates taken up are fully oxidized. The potential contribution of FFA oxidation to oxygen consumption ranged from $20 \%$ to $70 \%$. A significant decrease was seen in the first hour after removal of the crossclamp. The potential contribution of lactate oxidation to oxygen consumption ranged from $14 \%$ to
$26 \%$ and did not change during the study period. The potential contribution of glucose oxidation to oxygen consumption ranged from $5 \%$ to $65 \%$ and increased after crossclamp release (T2-T3). After removal of the clamp, the sum of the potential contribution of oxidation of all measured substrates was increased compared with values before crossclamping. The sum immediately after release of the clamp (T3) was $156 \%$, which was significantly different from $100 \%$, implying that more substrates were taken up than could be oxidized. In the hour after release of the clamp, this value decreased to $58 \%$ (T3 vs T5). At T1, T2, T5, and T6, the sum of the calculated oxygen consumption was significantly smaller than $100 \%$, which implies that the measured net balance of substrate uptake could not account for all the oxygen used by the heart.

Respiratory quotients and calculated oxidation rates (Table IV). The respiratory quotient was $0.85 \pm 0.2$ before the clamp was applied (T1 and T2) and increased to $1.00 \pm 0.2$ after release of the crossclamp (T4 and T5). This also implies that release of the crossclamp was associated with a shift to carbohydrate oxidation. 
Table IV. Data of gaseous exchange across the heart and calculations of carbohydrate and FFA oxidation in 18 patients (see appendix for formulas)

\begin{tabular}{|c|c|c|c|c|}
\hline & Before $X-O N(T 1, T 2)$ & & After $X-O F F(T 4, T 5)$ & $X-O F F+6 h(T 6)$ \\
\hline $\mathrm{VCO}_{2} \mathrm{a}-\mathrm{cs}(\mu \mathrm{mol} / \mathrm{L}$ blood $)$ & $-3715 \pm 825$ & $*+$ & $-2571 \pm 661$ & $-2844 \pm 503$ \\
\hline $\mathrm{Vo}_{2} \mathrm{a}-\mathrm{cs}(\mu \mathrm{mol} / \mathrm{L}$ blood $)$ & $4392 \pm 600$ & $*+$ & $2591 \pm 401$ & $3286 \pm 503$ \\
\hline Respiratory quotient & $0.85 \pm 0.2$ & $\dagger$ & $1.00 \pm 0.2$ & $0.88 \pm 0.2$ \\
\hline Carbohydrate oxidation as percentage of $\mathrm{VO}_{2} \mathrm{a}-\mathrm{cs}$ & $51 \pm 61$ & $\dagger$ & $101 \pm 78$ & $59 \pm 52$ \\
\hline FFA oxidation as percentage of $\mathrm{Vo}_{2} \mathrm{a}-\mathrm{cs}$ & $49 \pm 61$ & $\dagger$ & $-1 \pm 78$ & $41 \pm 52$ \\
\hline Carbohydrate oxidation ( $\mu \mathrm{mol} / \mathrm{min})$ & $46 \pm 57$ & $\dagger$ & $71 \pm 53$ & $51 \pm 47$ \\
\hline FFA oxidation $(\mu \mathrm{mol} / \mathrm{min})$ & $10 \pm 14$ & $\dagger$ & $1 \pm 13$ & $9 \pm 11$ \\
\hline
\end{tabular}

$F F A$, Free fatty acids; $X-O N$, crossclamp on; $X-O F F$, crossclamp off; $a$, arterial concentration; $c s$, coronary sinus concentration.

$* P<.001$ before $\mathrm{X}$-ON versus after $\mathrm{X}$-OFF.

$\dagger P=.03$ before $\mathrm{X}$-ON versus after $\mathrm{X}$-OFF.

$\ddagger P<.001$ before $\mathrm{X}$-ON versus $\mathrm{X}$-OFF +6 hours.

\section{Discussion}

The data in this study show that FFAs and lactate were the main fuels of the human heart in the period before coronary artery bypass graft (CABG) operations and 6 hours after removal of the aortic crossclamp. Glucose was only a minor fuel in both periods. This implies that the metabolism of these hearts was comparable with the metabolism of healthy human hearts, as previously reported. ${ }^{3}$ A clear change occurred in the first hour after $\mathrm{CABG}$ surgery. In that period the heart extracted more glucose (see arteriovenous balance in Table III) and oxidized more carbohydrate and less fat (see cardiac respiratory quotient data in Table IV) than in the preoperative period and 6 hours after CABG surgery. This transient period of increased glucose uptake and carbohydrate oxidation was accompanied by an increase in cardiac blood flow and a decrease in fractional oxygen extraction. Immediately after removal of the aortic crossclamp, more substrates were extracted by the heart than oxidized, indicating that there was a net accumulation of energy-rich substrates in the heart in that period.

Even in relatively healthy hearts protected with cold cardioplegic solution, we observed a hyperemic response in combination with decreased myocardial oxygen extraction after release of the aortic crossclamp. In the past these disturbances have been suggested to involve general mitochondrial dysfunction ${ }^{17,18}$ or even mitochondrial damage, arising during reperfusion of the previously ischemic cardiac tissue. ${ }^{17,18}$

The increased glucose uptake observed in this study is in agreement with experimental studies of myocardial metabolism after ischemia in animal models ${ }^{7,19-21}$ in which an increased glucose uptake was found after ischemia. The data also confirm the study of Teoh and associates, ${ }^{10}$ who found a decreased FFA oxidation in the first hour after crossclamp removal during cardiac surgery.
The observation made in this study that glucose is the preferential fuel in the first hour after CABG surgery strengthens the rationale for the clinical use of glucoseinsulin infusions after cardiac operations. ${ }^{22,23}$ The patients in this study had good left ventricular function and recovered quickly from the operation. The preferential use of glucose may be more pronounced and even be more essential for functional recovery of the heart in patients in whom cardiac function is reduced both before and after CABG. The observations made here may imply that the hyperemia of the heart after CABG serves to provide more of the preferential fuel (glucose) to the heart. This mechanism may be defective in hearts with reduced postoperative function. Glucose-insulin infusions in that case may provide important metabolic support and may help to improve postoperative cardiac function. When a temporary energy deficit in the first hour after CABG is the cause for the increase in blood flow and glucose uptake and when the energy problem is related to a suboptimal tricarboxylic acid cycle flux, ${ }^{24,25}$ then glutamate infusions could also form part of the metabolic strategies to support the heart after CABG surgery. 22,23

An alternative explanation for the change in substrate uptake and oxidation of the heart, not related to a temporary energy problem in the myocardial cells, is a change in substrate supply to the heart. In this study a decrease of FFA arterial concentration was observed after crossclamp removal. The arterial FFA concentration and the concentration gradient between the blood and cardiac tissue is a major determinant of FFA uptake and oxidation by the human heart. ${ }^{4}$ The decrease in arterial FFA concentration, therefore, can be a cause for the decrease in fat oxidation by the heart. This decrease in fat oxidation may, via the glucose-FFA cycle, ${ }^{4,26}$ also lead to the increase in glucose uptake and carbohydrate oxidation. An argument against this 
mechanism is that during the first measurement after crossclamp release, when glucose uptake reached peak levels, the FFA arterial concentration was similar to values before the clamp was applied.

The accuracy of coronary sinus flow as a measure of myocardial perfusion depends on the position of the catheter within the coronary sinus. ${ }^{27} \mathrm{~A}$ shift in catheter position will cause a change in measured flow. This limits the use of coronary sinus flow in comparing changes between individuals. However, the method has been proved accurate in recording changes within a studied subject. ${ }^{14}$ In this study special care was given to verify correct position of the catheter in the coronary sinus. The surgeon digitally checked the position of the catheter within the coronary sinus, thus excluding major errors resulting from catheter dislodgment. Small changes in catheter position cannot be excluded and may be a cause of the relatively large variance of the measurements. The changes we observed in flow were large and were consistently observed in all patients. The large changes in combination with the careful check of correct catheter position lead us to believe that the observed changes are a correct reflection of changes in myocardial perfusion.

Before the operation and between 2 and 6 hours after CABG, the myocardial substrate uptake (sum of FFAs, lactate, and glucose) did not fully account for the amount of oxygen used by the heart (Fig 3). Other compounds, which may have been oxidized, are ketone bodies and amino acids (minimal exchange only, data not shown). A potentially important fuel also are the fatty acids present in the triglycerides of very low density lipoprotein. These are liberated by lipoprotein lipase present on the membrane of the endothelial cells of the cardiac vascular bed. ${ }^{4}$ In the first eight patients we did not observe a significant arteriovenous difference for the plasma total triglyceride concentration and for the glycerol concentration (liberated during lipolysis) and, therefore, we did not attempt to quantitate the plasma triglyceride contribution in subsequent studies. However, the sum of these additional substrates, which are difficult to quantitate individually, may well cover the missing substrate oxidation in Fig 3.

This study shows that glucose is the preferential fuel of the human heart in the first hour after CABG surgery, whereas fatty acids and lactate are the main fuels before and 6 hours after CABG surgery, as in normal healthy hearts. There also is an increase in coronary blood flow in the first hour after CABG surgery, which may function to supply more of the preferential substrate to the heart. This finding seems to support the clinical use of glucose-insulin infusions to support the energy metabolism of the heart after CABG surgery. Further research is needed to investigate the underlying mechanism of the parallel increase in glucose uptake and coronary blood flow, because it may provide new information regarding metabolic strategies that can be used to support the human heart in the postoperative period.

\section{REFERENCES}

1. Van der Vusse GJ, Groot M. Interrelationship between lactate and cardiac fatty acid metabolism. Mol Cell Biochem 1992;116:11-7.

2. Taegtmeyer H, Roberts AFC, Raine AEG. Energy metabolism in reperfused heart muscle: metabolic correlates to return of function. J Am Coll Cardiol 1985;6:864-70.

3. Neely J, Morgan H. Relationship between carbohydrate and lipid metabolism and the energy balance of the heart muscle. Annu Rev Physiol 1974;36:413-59.

4. van der Vusse GJ, Glatz J, Stam H, Reneman RS. Fatty acid homeostasis in the normoxic and ischemic heart. Physiol Rev 1992;72:881-940.

5. Opie LH, Owen P, Riemersma RA. Relative rates of oxidation of glucose and free fatty acids by ischaemic and non-ischaemic myocardium after coronary artery ligation in the dog. Eur J Clin Invest 1973;3:419-35.

6. Liedtke AJ, Demaison L, Eggleston AM, Cohen LM, Nellis SH. Changes in substrate metabolism and effects of excess fatty acids in reperfused myocardium. Circ Res 1988;62:535-42.

7. Myears DW, Sobel BE, Bergmann SR. Substrate use in ischemic and reperfused canine myocardium: quantitative considerations. Am J Physiol 1987;253:H107-14.

8. Mickle DAG, del Nido PJ, Wilson GJ, et al. Exogenous substrate preference of the post-ischaemic myocardium. Cardiovasc Res 1986;20:256-63.

9. Schwaiger M, Schelbert HR, Keen R, et al. Retention and clearance of $\mathrm{C}-11$ palmitic acid in ischemic and reperfused canine myocardium. J Am Coll Cardiol 1985;6:311-20.

10. Teoh KH, Mickle DA, Weisel RD, et al. Decreased postoperative myocardial fatty acid oxidation. J Surg Res 1988;44:36-44.

11. Svensson SM, Svedjeholm RM, Ekroth RM, Milocco IM, Nilsson FM, Goran Sabel KM. Trauma metabolism and the heart. J Thorac Cardiovasc Surg 1990;99:1063-73.

12. Svensson S, Ekroth R, Milocco I, Nilsson F, Ponten J, Olsson GW. Glucose and lactate balances in heart and leg after coronary surgery: influence of insulin infusion. Scand J Thorac Cardiovasc Surg 1989;23:145-50.

13. Jynge P, Hearse DJ, de Leiris J, Feuvray D, Braimbridge MV. Protection of the ischemic myocardium. J Thorac Cardiovasc Surg 1978;76:2-15.

14. Baim D, Rothman M, Harrison D. Improved catheter for regional coronary sinus flow and metabolic studies. Am J Cardiol 1980;46:997-1000.

15. Bondar RJL, Mead DC. Evaluation of glucose-6-phosphate dehydrogenase from leuconostoc mesenteroides in the hexokinase method for determining glucose in serum. Clin Chem 1974; 20:586-90.

16. Pesce MA, Bodourian SH, Nicholson JF. Rapid kinetic measurement of lactate in plasma with a centrifugal analyzer. Clin Chem 1975;21:1932-4.

17. Kanter KB, Glower DD, Schaff HV, Gardner TJ. Mechanism of 
defective oxygen extraction following global ischemia. J Surg Res 1981;30:482-8.

18. Lucas SK, Kanter KR, Schaff HV, Elmer EB, Glower DD, Jr, Gardner TJ. Reduced oxygen extraction during reperfusion: a consequence of global ischemic arrest. J Surg Res 1980;28:43441.

19. Gorge G, Chatelain P, Schaper J, Lerch R. Effects of increasing degrees of ischemic injury on myocardial oxidative metabolism early after reperfusion in isolated rat hearts. Circ Res 1991;68: 1681-92.

20. Liedtke AJ, Renstrom B, Nellis SH, Hall JL, Stanley WC. Mechanical and metabolic functions in pig hearts after 4 days of chronic coronary stenosis. J Am Coll Cardiol 1995;26:815-25.

21. Schwaiger M, Schelbert HR, Ellison D, et al. Sustained regional abnormalities in cardiac metabolism after transient ischemia in the chronic dog model. J Am Coll Cardiol 1985;6:336-47.

22. Svedjeholm R, Hakanson E, Vanhanen I. Rationale for metabolic support with amino acids and glucose-insulin-potassium (GIK) in cardiac surgery. Ann Thorac Surg 1995;59:S15-22.

23. Svedjeholm R, Huljebrant I, Hakanson E, Vanhanen I. Glutamate and high-dose glucose-insulin-potassium (GIK) in the treatment of severe cardiac failure after cardiac operations. Ann Thorac Surg 1995;59:S23-30.

24. Lazar H, Buckberg G, Maganaro A, Becker H, Maloney J. Reversal of ischemic damage with amino acid substrate enhancement during reperfusion. Surgery 1980;88:702-9.

25. Rau E, Shine K, Gervais A, Douglas A, Amos E. Enhanced mechanical recovery of anoxic and ischemic myocardium by amino acid perfusion. Am J Physiol 1979;236:H873-9.

26. Randle PJ, Garland PB, Hales CN, Newsholme EA. The glucose fatty-acid cycle: its role in insulin sensitivity and the metabolic disturbances of diabetes mellitus. Lancet 1963;1:785-9.

27. Bagger J. Coronary sinus blood flow determination by the thermodilution technique: influence of catheter position and respiration. Cardiovasc Res 1985;19:27-31.

28. Frayn KN, Lund P, Walker M. Interpretation of oxygen and carbon dioxide exchange across tissue beds in vivo. Clin Sci (Colch) 1993;85:373-84.

29. Frayn KN. Calculation of substrate oxidation rates in vivo from gaseous exchange. J Appl Physiol 1983;55:628-34.

30. Bing RJ, Siegel A, Ungar I, Gilbert M. Metabolism of the human heart. II. Studies on fat, ketone and amino acid metabolism. Am J Med 1954;16:504-15

\section{Appendix}

Gaseous exchange. The measurement of oxygen uptake and carbon dioxide production across tissue beds yields information regarding the nature and quantity of the substrates oxidized in these tissues. Formulas were used as described by Frayn and associates. ${ }^{28,29}$ When glucose is oxidized according to the equation

Glucose $\left(\mathrm{C}_{6} \mathrm{H}_{12} \mathrm{O}_{6}\right)+6 \mathrm{O}_{2} \rightarrow 6 \mathrm{H}_{2} \mathrm{O}+6 \mathrm{CO}_{2}$

6 moles of oxygen are consumed and 6 moles of carbon dioxide are produced for each mole of glucose that is oxidized. The respiratory quotient is then 1.0. The oxidation of lactate according to the equation

$$
\text { Lactate }\left(\mathrm{C}_{3} \mathrm{H}_{6} \mathrm{O}_{3}\right)+3 \mathrm{O}_{2} \rightarrow 3 \mathrm{H}_{2} \mathrm{O}+3 \mathrm{CO}_{2}
$$

also gives a respiratory quotient of 1.0. The formulas subsequently given provide information about the net oxidation of carbohydrates in the heart, which will be the sum of glucose and lactate oxidation. It is assumed that FFAs rather than triacylglycerols are oxidized in the myocardium. For simplicity the average of oleic acid $\left(\mathrm{C}_{18} \mathrm{H}_{34} \mathrm{O}_{2}\right)$ and stearic acid $\left(\mathrm{C}_{18} \mathrm{H}_{36} \mathrm{O}_{2}\right)$ will be considered; that is, $\mathrm{C}_{18} \mathrm{H}_{35} \mathrm{O}_{2}$. The equation for complete FFA oxidation is:

$4 \mathrm{C}_{18} \mathrm{H}_{35} \mathrm{O}_{2}+103 \mathrm{O}_{2}+72 \mathrm{CO}_{2}+70 \mathrm{H}_{2} \mathrm{O}$

(respiratory quotient $=0.699$ )

The oxidation of amino acids in the myocardium can be estimated from the myocardial nitrogen release. However, it has been shown that the quantitative contribution of amino acids to energy contribution in the heart is small. ${ }^{30}$ Therefore, the contribution of amino acids was neglected. This means that if oxygen and carbon dioxide content in arterial and coronary sinus blood $\left(\mathrm{VO}_{2} \mathrm{a}-\mathrm{cs}\right.$ and $\left.\mathrm{VCO}_{2} \mathrm{a}-\mathrm{cs}\right)$ are known, the relative contribution of carbohydrates and FFAs can be calculated from two formulas with two unknown parameters. If the oxidation rate of glucose per liter blood flow is $\mathrm{G}(\mu \mathrm{mol} / \mathrm{L})$ and the FFA oxidation per liter blood flow is $\mathrm{F}(\mu \mathrm{mol} / \mathrm{L})$, then:

$\mathrm{VO}_{2} \mathrm{a}-\mathrm{cs}(\mu \mathrm{mol} / \mathrm{L})=6 \times \mathrm{G}+(103 / 4) \times \mathrm{G}$

$\mathrm{VCO}_{2} \mathrm{a}-\mathrm{cs}(\mu \mathrm{mol} / \mathrm{L})=6 \times \mathrm{G}+(72 / 4) \times \mathrm{F}$

These equations can be converted into:

$\mathrm{G}(\mu \mathrm{mol} / \mathrm{L})=0.553 \times \mathrm{VCO}_{2} \mathrm{a}-\mathrm{cs}-0.387 \times \mathrm{Vo}_{2} \mathrm{a}-\mathrm{cs}$

$\mathrm{F}(\mu \mathrm{mol} / \mathrm{L})=0.129 \times\left(\mathrm{Vo}_{2} \mathrm{a}-\mathrm{cs}-\mathrm{VCO}_{2} \mathrm{a}-\mathrm{cs}\right)$

The relative contribution of carbohydrate and FFA oxidation to oxygen consumption can be derived from these formulas. These relative contributions are independent of the measured coronary sinus flow (see also Table IV).

Relative contribution of glucose to $\mathrm{VO}_{2} \mathrm{a}-\mathrm{cs}=100 \times$ $(\mathrm{G} \times 6) /\left(\mathrm{O}_{2} \mathrm{a}-\mathrm{cs}\right)$

Relative contribution of FFA to $\mathrm{VO}_{2} \mathrm{a}-\mathrm{cs}=100 \times$ $(\mathrm{F} \times 25.7) /\left(\mathrm{O}_{2} \mathrm{a}-\mathrm{cs}\right)$

Multiplying formulas (6) and (7) with the coronary sinus blood flow in liters per minute gives the absolute oxidation rate of carbohydrates and FFAs in micromoles per minute (see also Table IV):

Glucose oxidation rate $(\mu \mathrm{mol} / \mathrm{m})=\mathrm{G}(\mu \mathrm{mol} / \mathrm{L}) \times$ cs flow $(\mathrm{L} / \mathrm{m})$

FFA oxidation rate $(\mu \mathrm{mol} / \mathrm{m})=\mathrm{F}(\mu \mathrm{mol} / \mathrm{L}) \times$ cs flow $(\mathrm{L} / \mathrm{m})$

Substrate oxygen equivalents $\left(\mathrm{Vo}_{\text {2equivalents }}\right)$. To assess whether oxidation of FFAs, glucose, and lactate could explain the amount of oxygen taken up by the heart, we calculated the amount of oxygen necessary for full oxidation of these three substrates. The oxygen equivalents of these substrates taken up were calculated by multiplying the arterial-coronary sinus difference of the substrate extracted with the amount of oxygen necessary for full oxidation of the substrate and the fac- 
tor (1 - hematocrit). The correction for hematocrit was necessary to enable the comparison of arterial-coronary sinus differences measured in plasma (glucose, lactate, and FFAs) with arterial-coronary sinus differences measured in whole blood (oxygen). It was assumed that the oxidation of $1 \mathrm{~mol}$ of FFA uses $25.7 \mathrm{~mol}$ of oxygen, $1 \mathrm{~mol}$ of lactate uses $3 \mathrm{~mol}$ of oxygen, and $1 \mathrm{~mol}$ of glucose uses $6 \mathrm{~mol}$ of oxygen. These oxygen equivalents were then expressed as a percentage of the measured $\mathrm{O}_{2} \mathrm{a}-\mathrm{cs}$. The calculated figures have no dimension and are flow independent. As an example, the formula for the glucose oxygen equivalent as percentage of measured $\mathrm{O}_{2} \mathrm{a}-\mathrm{cs}\left(\mathrm{G}_{\mathrm{O} 2 \mathrm{eq}} \%\right)$ is given (see also Fig 3).

$$
\begin{aligned}
& \mathrm{G}_{\mathrm{o} 2 \mathrm{eq}} \%=\frac{\text { Glucose uptake }(\mu \mathrm{mol} / \mathrm{min})(\mathrm{Ga}-\mathrm{cs} \times[1-\mathrm{Hct}] \times \mathrm{cs} \text { flow })}{\mathrm{O}_{2} \text { consumption }(\mu \mathrm{mol} / \mathrm{min})\left(\mathrm{O}_{2} \mathrm{a}-\mathrm{cs} \times \mathrm{cs} \text { flow }\right)} \quad(\mathrm{Eq} 12) \\
& \times 100 \% \\
& \mathrm{G}_{\mathrm{o} 2 \mathrm{eq}} \%=\frac{\text { Glucose } \mathrm{a}-\mathrm{cs}(\mu \mathrm{mol} / \mathrm{L}) \times(1-\mathrm{Hct}) \times 6}{\mathrm{O}_{2} \mathrm{a}-\mathrm{cs}(\mu \mathrm{mol} / \mathrm{L})} \times 100 \%
\end{aligned}
$$

\section{Availability of Journal back issues}

As a service to our subscribers, copies of back issues of The Journal of Thoracic and Cardiovascular Surgery for the preceding 5 years are maintained and are available for purchase from Mosby at a cost of $\$ 17.00$ per issue until inventory is depleted. The following quantity discounts are available: $25 \%$ off on quantities of 12 to 23, and one third off on quantities of 24 or more. Please write to Mosby, Inc, Subscription Services, 11830 Westline Industrial Drive, St Louis, MO 63146-3318, or call 800-453-4351 or 314-453-4351 for information on availability of particular issues. If unavailable from the publisher, photocopies of complete issues may be purchased from Bell \& Howell Information and Learning, 300 N Zeeb Rd, Ann Arbor, MI 48106-1346, 734-761-4700. 